\title{
GESTÃO DAS EMPRESAS RURAIS CAFEEIRAS NO ESTADO DO PARANÁ
}

Management of rural coffee companies in the state of Paraná

Antonio Bliska Júnior

Dimas Soares Júnior

Patrícia Helena Nogueira Turco

Flávia Maria de Mello Bliska 


\title{
GESTÃo DAS EMPRESAS RURAIS CAFEEIRAS NO ESTADO DO PARANÁ
}

\author{
Management of rural coffee companies in the state of Paraná
}

\author{
Antonio Bliska Júnior \\ Dimas Soares Júnior \\ Patrícia Helena Nogueira Turco \\ Flávia Maria de Mello Bliska
}

\begin{abstract}
Resumo: A cafeicultura é relevante na oferta de ocupações e na formação da renda de um grande número de pequenos municípios do estado do Paraná. Para a sustentabilidade e competitividade da atividade cafeeira, é muito importante que as empresas baseiem suas atividades em sistemas de gestão acurados. Este estudo analisa o grau de gestão das empresas rurais cafeeiras paranaenses, o comportamento dos critérios de gestão nas principais regiões do Estado e identifica os indicadores de gestão que tem contribuído com maior peso para os níveis de gestão observados, visando orientar principalmente as atividades públicas e privadas voltadas à promoção do desenvolvimento local e regional. O estudo baseia-se na aplicação do Método de Identificação do Grau de Gestão - MIGG Café, estatísticas descritivas e análise de componentes principais. Os resultados, independentemente do tipo de café ou região do Paraná, apontam para um amplo potencial de crescimento das práticas de gestão.
\end{abstract}

Palavras-chaves: Planejamento agrícola; Competitividade; Sustentabilidade.

\begin{abstract}
Coffee cultivation is relevant in the provision of occupations and income in a large number of small counties in the state of Paraná. For sustainability and competitiveness of the coffee business, it is very important that firms base its activities on accurate management systems. This study analyse the degree of management of rural coffee firms in the Paraná state, the behaviour of the management criteria in its main regions and identifies the management indicators that have contributed with greater weight to the levels of management observed, aiming mainly to orient the activities of public and private initiatives to promote local and regional development. The study is based on the Identification Method of Management Degree - MIGG Coffee, descriptive statistics and principal component analysis. The results, regardless of the type of coffee or Paraná evaluated region, point to a large potential for growth management practices.
\end{abstract}

Key words: Agricultural planning; Competitiveness; Sustainability.

Resumen: El cultivo de café es relevante para la ocupación y la formación de ingresos de una gran cantidad de pequeños municipios en el estado de Paraná. Para la sostenibilidad y competitividad de la actividad cafetalera, es muy importante que las empresas basen sus actividades en sistemas de gestión precisos. Este estudio analiza el grado de gestión de las empresas rurales de café de Paraná, el comportamiento de los criterios de gestión en las principales regiones del estado e identifica los indicadores de gestión que más han contribuido a los niveles de gestión observados, con el objetivo principal de guiar al público y dirigido a promover el desarrollo local y regional. El estudio se basa en la aplicación del Método de Identificación del Grado de Gestión - MIGG Café, estadísticas descriptivas y análisis de componentes principales. Los resultados, independientemente del tipo de café o región de Paraná, apuntan a un amplio potencial de crecimiento de las prácticas de gestión.

Palabras clave: Planificación agrícola; Competitividad; Sostenibilidad. 
IGepec, Toledo, V. 24, n.1, p. 27-52, jan./jun. 2020. 


\section{INTRODUÇÃO}

A lavoura cafeeira, introduzida no Brasil em 1727, chegou efetivamente ao estado do Paraná no início do século XX, na mesorregião hoje conhecida como Norte Pioneiro, embora existam relatos de introduções anteriores. Entre 1911 e 1920 houve forte incremento na produção, comparável ao ocorrido no estado de São Paulo 100 anos antes. Do final da II Guerra Mundial até a grande geada de 1975 o Paraná assumiu a liderança da produção nacional. No período 1970-1996 o café cedeu espaço às lavouras de soja e milho (VEGRO e BLISKA, 2007).

Em 2018 o Brasil colheu 61,7 milhões de sacas de 6o quilos de café beneficiado, 77,0\% de arábica - Coffea arabica, (47,5 milhões sacas) e 23,0\% de conilon - Coffea canephora, (14,2 milhões de sacas). A contribuição do Paraná foi estimada em 1,0 milhão de sacas de arábica, correspondentes a 1,6\% do volume total de café arábica produzido no País e a 2,3\% da área total de arábica. Foram destinados à lavoura cafeeira 40,8 mil hectares, com 37,5 mil ha em produção. A produtividade média da lavoura foi de 26,7 sacas/ha e renda bruta estimada em $\mathrm{R} \$ 404,5$ milhões (CONAB, 2018). As microrregiões de Ibaiti, Jacarezinho e Wenceslau Braz no Norte Pioneiro tem se destacado como as principais regiões produtoras de café no Estado (IBGE, 2019c). As lavouras cafeeiras estão presentes em 224 municípios do Paraná, distribuída em 9.865 estabelecimentos com café arábica e em 222 estabelecimentos com café conilon (IBGE, 2019a).

Segundo os últimos Censos Agropecuários, em 2006 existiam no estado do Paraná 20.488 estabelecimentos cafeeiros, 78\% desses identificados como unidades familiares de produção, número que se reduziu para 11.694 em 2017. Considerando que um sistema de gestão acurado é de extrema importância para a sustentabilidade da atividade agrícola, principalmente diante dos desafios observados nos processos de sucessão familiar, a criação de mecanismos de gestão interna é fundamental, desde o aperfeiçoamento dos processos agrícolas até a colocação do produto no mercado.

Alguns indicadores de gestão estão estreitamente relacionados a benefícios resultantes da adoção de programas de certificação agrícola, tais como a garantia ao consumidor sobre os atributos do produto e, na produção agrícola, o maior acesso ao mercado, maior treinamento de colaboradores, utilização racional de agroquímicos e de outros fatores de produção e maior proteção ambiental (CARLI, OLIVEIRA e DIAS, 2013).

Outros indicadores de gestão refletem aspectos relacionados à Segurança e Saúde do Trabalhador (SST). Em geral tratados entre as atividades administrativas, deveriam receber maior atenção, tendo em vista os riscos físicos, químicos, biológicos, de acidentes e ergonômicos a que os trabalhadores estão expostos nas atividades típicas do segmento agrícola. Além disso, com o aumento do uso de máquinas, os trabalhadores ficam expostos a outros riscos, tais como ruído e vibrações, e sujeitos a acidentes, como o tombamento de máquinas (PASTORE, 2011; MF/DATAPREV, 2015; DIEESE, 2016).

Em função da importância econômica e social do segmento cafeeiro para o estado do Paraná e considerando-se que um sistema de produção sustentável em todas as suas etapas deve atender a processos socialmente justos, economicamente viáveis e ambientalmente adequados, este estudo tem por objetivo mapear o grau de gestão das propriedades cafeeiras do estado do Paraná e identificar os indicadores que tem contribuído com maior peso para os níveis de gestão, visando orientar principalmente as atividades de assistência técnica e extensão rural e as políticas de desenvolvimento local e regional. 


\section{BREVE HISTÓRICO DA CAFEICULTURA NO PARANÁ}

A história do café no Paraná se confunde muitas vezes com a história da ocupação das mesorregiões Norte Pioneiro, Norte Central e Noroeste Paranaenses, as quais podem ser visualizadas na Figura 1, na qual são apresentadas também as microrregiões com empresas cafeeiras avaliadas neste artigo.

Ainda que os primeiros plantios comerciais tenham sido registrados em 1884 no atual município de Tomazina, na microrregião hoje denominada Wenceslau Braz, Norte Pioneiro do Estado (POZZOBON, 2006), é somente a partir de 1904 que o café começa a ganhar espaço efetivo na economia estadual, em processo identificado por Kohlhepp et al. (2014, p.81) como “... um clássico desdobramento da economia cafeeira tradicional paulista."

Com efeito, fazendeiros mineiros que se estabeleceram naquela região paranaense ainda nos últimos decênios do século XIX, dedicando-se, sobretudo, ao cultivo de cereais e à produção e comércio de suínos, valeram-se na introdução de suas lavouras do modelo técnico e social vigente no estado vizinho, aproveitando as oportunidades trazidas pela conjunção de dois importantes acontecimentos: o "Convênio de Taubaté", firmado em 1906, que trazia uma série de políticas de valorização da cafeicultura, entre as quais o compromisso de que São Paulo, Minas Gerais e Rio de Janeiro, os maiores produtores de então, suspenderiam por cinco anos a implantação de novos cafeeiros; e a chegada em 1908 da Estrada de Ferro Sorocabana ao município de Ourinhos, na divisa com o estado paulista, permitindo assim o acesso ao Porto de Santos (WACHOWICZ, 2002; POZZOBON, 2006; STECA e FLORES, 2002).

Figura 1 - Mesorregiões geográficas paranaenses com produção de café e microrregiões geográficas paranaenses com empresas cafeeiras avaliadas com o Método de Identificação do Grau de Gestão - MIGG Café

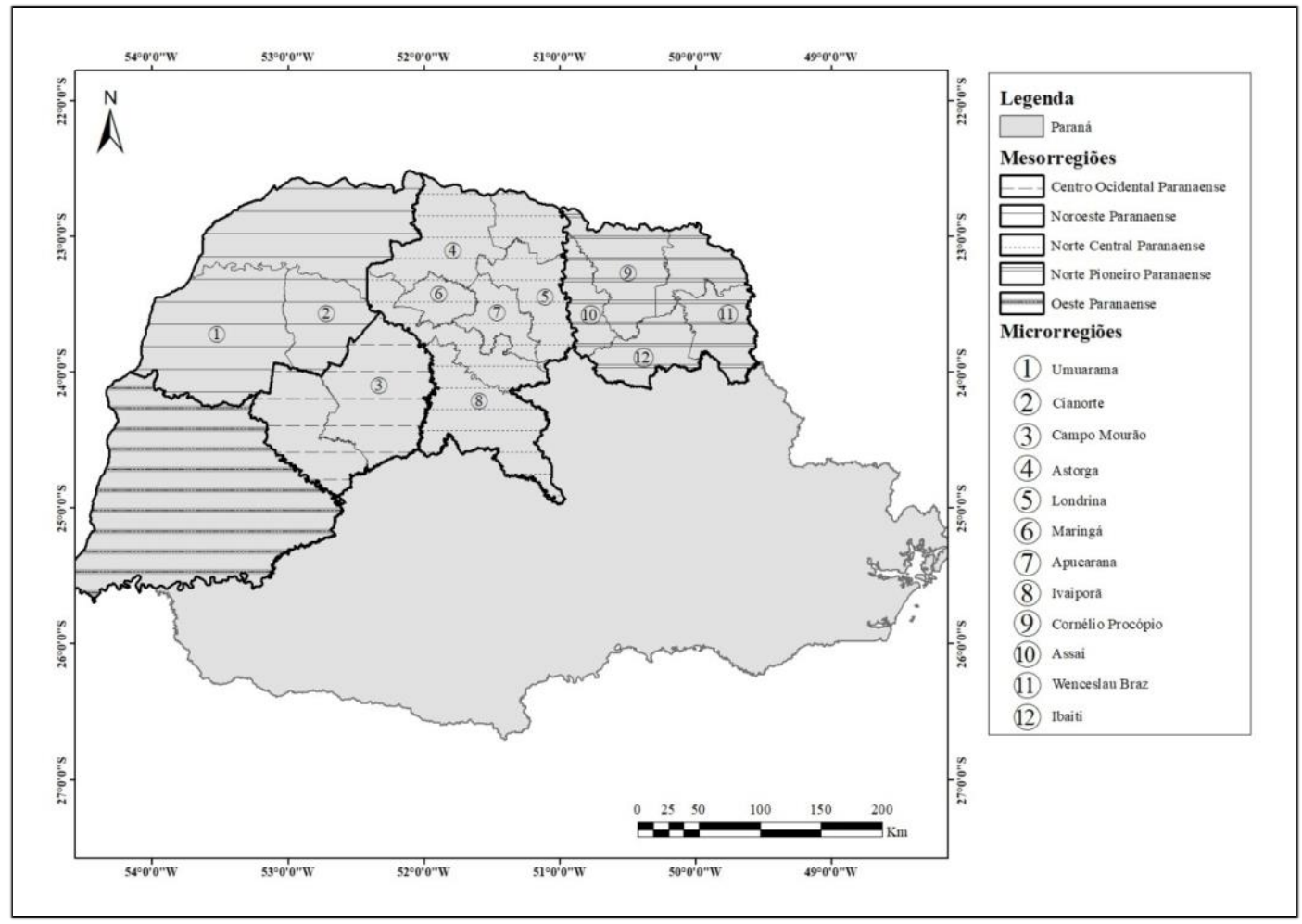

Fonte: Elaborado pelos autores a partir de dados do IBGE (2019b). 
Mesmo que incipiente esse primeiro ciclo de expansão consolidou a atividade no Paraná, prenunciando a importância que conquistaria nas décadas seguintes, de tal sorte que o estado se insere no cenário produtivo nacional, sendo que no plano estadual o café equipara-se em 1935 à erva-mate, produto tradicional, porém então decadente, na receita fiscal do Estado (WACHOWICZ, 2002).

Ainda na década de 1930, com o inicio da colonização das hoje denominadas mesorregiões Norte Central e Noroeste, conduzida de modo dirigido por empresas em sua maioria de capital privado, o café se torna o principal fator de conformação da paisagem e das estruturas social e agrária na frente norte de ocupação do Paraná, empregando para tanto um modelo técnico e socioeconômico inovador no contexto nacional, seja pelas variedades escolhidas, densidades das lavouras e forte tendência de diversificação das áreas de cultivo, mas, sobretudo, por ser o café baseado em pequenas e médias propriedades (KOHLHEPP et al., 2014).

Com efeito, em 1961, 73\% dos empreendimentos cafeeiros paranaenses possuíam menos que 16.000 plantas em área perto de 22 ha; $15 \%$ dos deles tinham entre 16.000 e 32.000 cafeeiros, em 44 ha; e o café representava perto de $71 \%$ da área total dos estabelecimentos (KOHLHEPP et al., 2014).

$\mathrm{O}$ avanço desse modelo produtivo permitiu em seu apogeu o estabelecimento de cerca de 200 municípios cafeeiros (POZZOBON, 2006) e galgou o Paraná ao longo das décadas de 1940 a 1950 às primeiras posições entre os principais produtores do país, assumindo em 1959 a condição de maior produtor nacional, condição mantida quase ininterruptamente até 1975, tendo sido o responsável por $58 \%$ da produção brasileira em 1962 e 1969 (Gráfico 1). 
Gráfico 1 - Evolução da participação relativa do estado do Paraná na produção brasileira de café e sua posição no ranking de produção nacional. 1931-2018

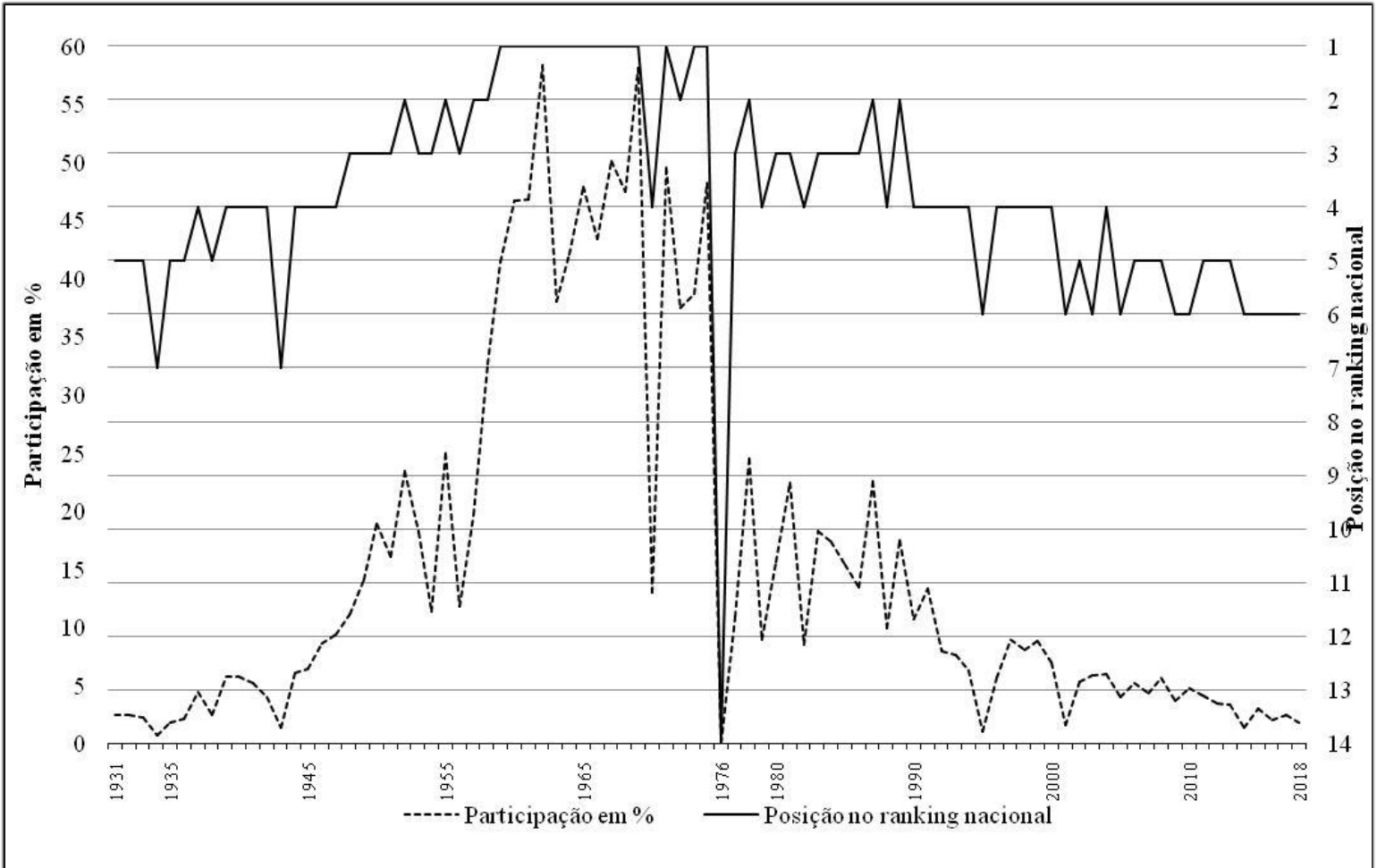

Fonte: Elaborado pelos autores a partir de dados do IBGE (2019c).

Ainda que já se encontrasse diante de problemas relacionados às ocorrências de geadas, suaves e moderadas, redução da produtividade em decorrência da perda da fertilidade natural dos solos, mudanças na legislação trabalhista e implantação da política nacional de erradicação de lavouras cafeeiras, foi com a grande geada negra de 1975 que a cafeicultura do Paraná encontrou o seu grande ponto de inflexão, pressionada também na mesorregião Norte Central pela forte concorrência da produção de soja, milho e trigo na ocupação das áreas mecanizáveis atividades que se mantém até hoje na base dos sistemas produtivos ali praticados. Assim sendo, a geada negra de 1975 marca não somente o inicio do declínio da produção paranaense no cenário nacional, como também uma nova composição na importância relativa das principais mesorregiões produtoras, com a mesorregião Noroeste assumindo a liderança na produção da maioria das safras entre 1977 e 1992 e participação residual da mesorregião Oeste, com a contribuição média de $4 \%$ no total produzido no estado ao longo do período analisado (Gráfico 2).

A ocorrência de outra geada severa no inicio dos anos 1990 não só reduz a participação da produção paranaense no plano nacional à casa de um dígito, como também impacta fortemente a atividade na mesorregião Noroeste. Assim, o Norte Central recupera a hegemonia produtiva entre 1993 e 2003, secundado de perto nesse período não mais pelo Noroeste, mas sim pelo Norte Pioneiro do estado.

Todavia, a partir dos anos 2000 essa mesorregião onde teve inicio a cafeicultura do Paraná conquistará a condição de principal produtora, respondendo na média das últimas cinco safras (2014-2018) por 68\% do volume total produzido no estado, sendo que suas microrregiões de Ibaiti e Wenceslau Braz são as únicas microrregiões paranaenses identificadas como especializadas na produção de café em estudo em nível nacional com base nas safras 2014 e 2015 (VOLSI et al. 2019). 
Gráfico 2 - Evolução da participação relativa das mesorregiões cafeeiras na produção total de café do estado do Paraná. 1974-2018

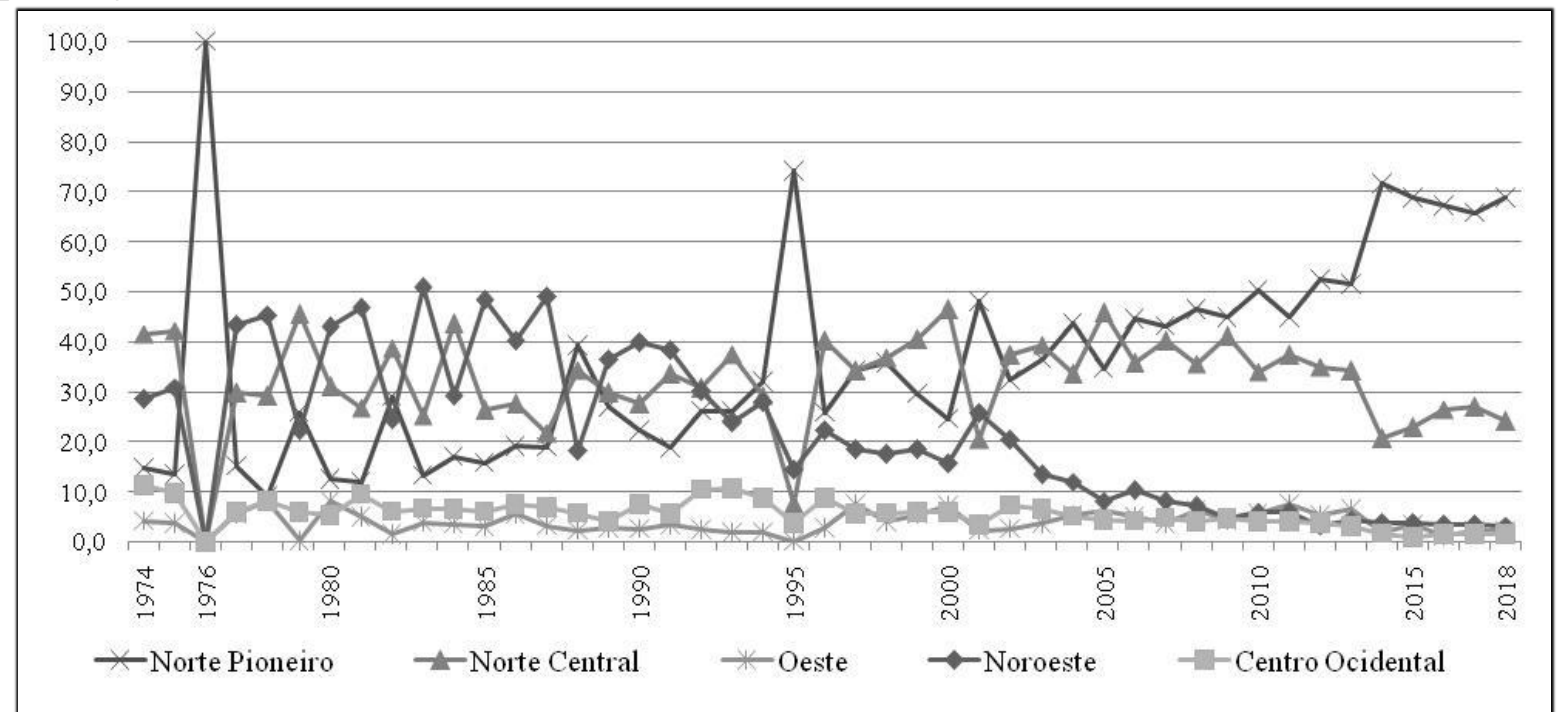

Fonte: Elaborado pelos autores a partir de dados de IBGE (2019c).

Vale ressaltar que essa posição de destaque da mesorregião Norte Pioneiro na produção de café no Paraná, tem sido marcada também pela estabilização na área colhida, ao contrário do declínio constatado em outras mesorregiões (IBGE, 2019c), e ainda pelas iniciativas voltadas à produção de cafés especiais, com a criação em 2008 da Associação de Cafés Especiais do Norte Pioneiro do Paraná (ACENPP), cuja atuação resultou na obtenção, em 2012, da única indicação de procedência (IP) do café paranaense, o café "Norte Pioneiro do Paraná" (BRONZERI; BULGACOV, 2014). 


\section{METODOLOGIA}

Para avaliar o nível de gestão das empresas cafeeiras utilizou-se o Método de Investigação do Grau de Gestão para Café - MIGG Café (BLISKA JÚNIOR et al, 2015). O MIGG baseia-se na identificação do nível de gestão de uma empresa de acordo com pontuação obtida mediante aplicação de um questionário. Esse questionário avalia 64 indicadores (Quadro 1), referentes a oito critérios de gestão, relacionados a processos gerenciais, enumerados seguir:

- Planejamento: se refere à orientação e execução de estratégias, cumprimento de metas, definição e acompanhamento dos planos para o seu êxito.

- $\quad$ Liderança: trata da orientação filosófica da organização, controle externo sobre sua direção e controle de resultados pela mesma.

- $\quad$ Clientes: aborda o tratamento de informações de clientes e do mercado.

- Sociedade: engloba o respeito e tratamento das demandas sociais e ambientais.

- Informações e conhecimento: aborda processos referentes à organização das demandas por informação e desenvolvimento de diferenciais competitivos.

- Pessoas: aborda as configurações de equipes de alto desempenho, desenvolvimento de competência das pessoas e manutenção de seu bem-estar.

- Processos: se refere aos procedimentos de negócio e aos de apoio, tratando separadamente aqueles relativos aos fornecedores e os econômicofinanceiros.

- Resultados: aborda séries históricas de resultados da organização e referenciais comparativos pertinentes, para avaliar os níveis de desempenho associados aos principais requisitos das partes interessadas, e verificar o atendimento das demandas de mercado.

Cada um dos critérios proporciona à avaliação do respondente uma soma de pontos cuja soma varia de zero a 1000 pontos. Essa pontuação classifica o grau de gestão em níveis de um a nove, sendo um o mais baixo e nove o mais elevado (BLISKA JÚNIOR et al., 2015).

O MIGG foi aplicado em formulários impresso e eletrônico. Este último fornece a pontuação, o grau de gestão e as recomendações de ações corretivas, priorizadas de acordo com o tempo em que devem ser realizadas, imediatamente após o seu preenchimento. O impresso foi aplicado principalmente no "Dia de Campo Sobre Mecanização da Cafeicultura Adensada” (Londrina, 2015 - Instituto Agronômico do Paraná/IAPAR, apoio Consoagro/Empresa Júnior da Universidade Estadual de Londrina/UEL e Instituto Paranaense de Assistência Técnica e Extensão Rural/Emater/PR) e na "Feira Internacional de Cafés Especiais do Norte Pioneiro/Ficafé" (Jacarezinho, 2015 - Serviço Brasileiro de Apoio às Micro e Pequenas Empresas/SEBRAE/PR, Associação dos Cafés Especiais do Norte Pioneiro do Paraná/ACENPP e Cooperativa de Cafés Especiais dos Produtores do Norte Pioneiro do Paraná/COCENPP).

O planejamento amostral foi realizado considerando o número de propriedades cafeeiras no Brasil e nos estados, apurado pelo Censo Agropecuário de 2006. Nas amostragens por área, produção ou valor da produção, além do viés originado pela subjetividade do levantamento do IBGE (Instituto Brasileiro de Geografia e Estatística) na pesquisa de Produção Agrícola Municipal, haveria o viés gerado pelas regiões que concentram pequeno número de grandes cafeicultores. Ao valor da produção, soma-se o possível viés ocasionado pelos cafés considerados especiais, com maior valor agregado. No caso do número de propriedades, o possível viés é o fato dos dados terem sido obtidos há dez anos, embora a cafeicultura seja cultura perene. 
Quadro 1 - Indicadores de gestão que compõem o Método de Identificação do Grau de Gestão - MIGG Café, por critério de gestão*

\begin{tabular}{|c|c|c|c|}
\hline \multicolumn{2}{|r|}{ Critério / Indicador de gestão } & \multicolumn{2}{|r|}{ Critério / Indicador de gestão } \\
\hline \multirow{4}{*}{ 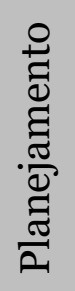 } & 01. Plano de Negócio & \multirow{20}{*}{ 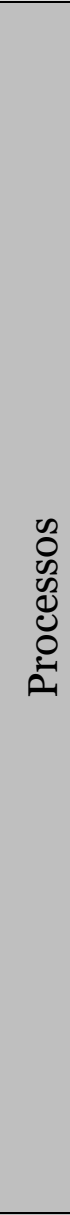 } & 34. Uso de material genético aprimorado \\
\hline & 02. Missão, Visão e Valores da empresa & & 35. Uso e teste de variedades \\
\hline & o3. Planejamento & & 36. Certificados de mudas e sementes \\
\hline & 04. Índices de ajuste da produção & & 37. Controle nutricional regular \\
\hline \multirow{5}{*}{ 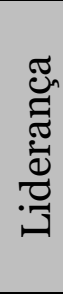 } & 05. Administração justa & & 38. Uso de equipamentos de precisão \\
\hline & 06. Solução de atritos & & 39. Orientação adequada para colheita \\
\hline & 07. Comunicação de objetivos e resultados & & 40. Colheita de grãos sem contato com solo \\
\hline & $\begin{array}{l}\text { o8. Informações sobre fatores de } \\
\text { produção }\end{array}$ & & 41. Transporte adequado dos grãos colhidos \\
\hline & 09. Obrigações e responsabilidades & & 42. Unidade de pós-colheita adequada \\
\hline \multirow{6}{*}{ } & 10. Definição de valores de venda & & 43. Avalição dos parâmetros de secagem \\
\hline & 11. Avaliação regular de produtos & & 44. Armazenamento adequado do café \\
\hline & 12. Telefone visando clientes & & 45. Avaliação do produto na armazenagem \\
\hline & 13. Histórico dos clientes & & 46. Inspeções de controle de qualidade \\
\hline & 14. Reclamações dos clientes & & 47. Manutenção preventiva \\
\hline & 15. Solução de falhas de entregas & & 48. Organização e limpeza do ambiente \\
\hline \multirow{6}{*}{ 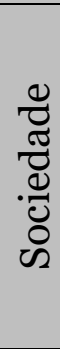 } & 16. Uso racional de agroquímicos & & 49. Controle da qualidade \\
\hline & 17. Descarte adequado de água e resíduos & & 50. Histórico dos volumes colhidos \\
\hline & 18. Idade mínima de colaboradores & & 51. Uso de crédito agrícola \\
\hline & $\begin{array}{l}\text { 19. Participação em cooperativa ou } \\
\text { associação }\end{array}$ & & 52. Uso de seguro agrícola \\
\hline & 20. Taxas e impostos em ordem & & 53. Acompanhamento das vendas \\
\hline & 21. Mecanismos para assegurar à ética & \multirow{11}{*}{ 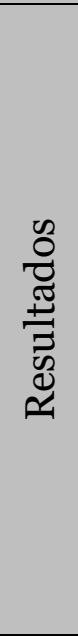 } & 54. Evolução da receita \\
\hline \multirow{6}{*}{ 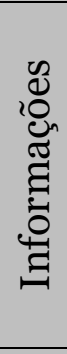 } & 22. Uso de assistência pública e privada & & 55. Satisfação dos clientes diretos \\
\hline & 23. Uso da internet & & 56. Relacionamento com o mercado \\
\hline & 24. Participação em eventos & & 57. Reputação da empresa \\
\hline & 25. Contato regular com clientes & & 58. Regulamentações ambientais \\
\hline & $\begin{array}{l}\text { 26. Novas oportunidades de } \\
\text { comercialização }\end{array}$ & & 59. Bem estar dos colaboradores \\
\hline & 27. Protocolos de tecnologias e processos & & 60. Avaliação da produtividade \\
\hline \multirow{6}{*}{ 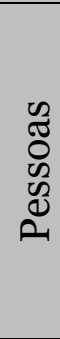 } & 28. Uso regular e correto de E.P.Is & & 61. Percentual de grãos por classes de padrão \\
\hline & 29. Plano de saúde aos colaboradores & & 62. Eficiência operacional \\
\hline & $\begin{array}{l}\text { 30. Formação e treinamento de } \\
\text { colaboradores }\end{array}$ & & Qualidade dos services recebidos \\
\hline & 31. Liderança entre colaboradores. & & 64. Ações corretivas dos fornecedores \\
\hline & 32. Desempenho de colaboradores & & adores destacados: relacio \\
\hline & 33. Remuneração de colaboradores & & Segurança e Saúde do Trabalho (SS' \\
\hline
\end{tabular}

Fonte: Bliska Júnior et al. (2015). 
Tendo em vista o ineditismo do tema - gestão na produção de café - o estudo é exploratório, a amostragem intencional e o levantamento não-probabilístico por conveniência, pois foram entrevistados apenas empresários que aceitaram participar do estudo.

O tamanho da amostra foi calculado de acordo com Bolfarine e Bussab (2005). A divisão de uma população em estratos ajuda a isolar a atuação das peculiaridades dos grupos de elementos que influenciam na variável resposta e acaba por diminuir a variância do estimador do parâmetro, mas para isso é necessário conhecimento prévio das características dos elementos que compõem a população. Como não há estudo probabilístico sobre a natureza da variável aleatória "qualidade da gestão nas empresas cafeeiras", não se conhece a distribuição de probabilidade para se expressar o estimador desse parâmetro, não sendo possível saber se há diferença estatística no nível de gestão entre as regiões, o que impede que se afirme que o Nível de Gestão seja homogêneo na população a ser estudada.

Primeiramente calculou-se o tamanho mínimo da amostra, de acordo com o Banco de Dados Agregados do IBGE (Tabela 1821 - IBGE, 2006), segundo "amostra aleatória simples", $(\bar{y})$, pois não se sabe se as regiões de interesse para o estudo podem ser caracterizadas como estratos amostrais.O estimador da média para a amostra aleatória simples é $\bar{y}=\frac{\sum y_{i}}{n}$. A variância desse estimador pode ser escrita como:

$$
\operatorname{var}(\bar{y})=\left(\frac{N-n}{N}\right) \frac{S^{2}}{n}
$$

Sendo $S^{2}$ a variância populacional. Como não se tem conhecimento desse valor, será utilizada a estimativa não viesada, que pode ser escrita como:

$$
s^{2}=\frac{\sum\left(y_{i}-\bar{y}\right)^{2}}{n-1}
$$

Isolando-se o $n$ da equação (1) e utilizando-se o estimador não viesado da variância populacional (equação B), obtém-se:

$$
n=\frac{N z^{2} s^{2}}{N B^{2}+z^{2} s^{2}}
$$

Em que $N=190.557$ e o limite de erro de estimação igual a $\pm 0,1$.

De acordo com o Teorema do Limite Central, quanto maior o tamanho amostral, mais a distribuição amostral do estimador da média se aproximará de uma distribuição Normal. Assim, foi utilizado em $z$, o quantil amostral da distribuição Normal, ao nível de confiança de $90 \%$, ou seja, $z=1,28$. Calculando-se a variância amostral dos 382 dados obtidos até a data de realização do planejamento amostral, temos, $s^{2}=$ 3,4847398

Substituindo-se os valores acima na equação (3) obteve-se o tamanho amostral para estimativa da média do Nível de Gestão segundo "amostra aleatória simples, para $B=0,1, n=569$. O valor estimado de $n$ foi dividido proporcionalmente entre as mesorregiões. Do ponto de vista teórico, assumindo-se a estratégia de amostragem estratificada pela distribuição de cafeicultores em mesorregiões, existem "principais mesorregiões geográficas de produção", de acordo com a classificação do IBGE, ou seja, aquelas que concentram 90\% das propriedades cafeeiras do Brasil (arábica e conilon). As mesorregiões cafeeiras brasileiras, respectivas porcentagens do total de propriedades cafeeiras no Brasil e os totais amostrados em cada mesorregião são apresentados no Quadro 2. 
Quadro 2 - Estratificação da amostra para as mesorregiões geográficas brasileiras com destaque para as mesorregiões localizadas no Estado do Paraná

\begin{tabular}{|c|c|c|c|c|c|}
\hline Mesorregião & $\begin{array}{l}\text { Número de } \\
\text { propriedades } \\
\text { cafeeiras } \\
\text { (\%) }\end{array}$ & $\%$ acumulada & $\begin{array}{c}\text { Amostra } \\
\text { efetiva }\end{array}$ & $\begin{array}{l}\text { Amostra } \\
\text { estimada } \\
(B)=0,1\end{array}$ & Diferença \\
\hline Sul/Sudoeste de Minas MG & 17,46 & 17,46 & 223 & 99 & 124 \\
\hline Zona da Mata MG & 14,64 & 32,1 & 133 & 83 & 50 \\
\hline Central Espírito-santense ES & 7,31 & 39,41 & 50 & 42 & 8 \\
\hline Leste Rondoniense RO & 7,2 & 46,61 & 8 & 41 & -33 \\
\hline Sul Espírito-santense ES & 6,94 & 53,55 & 53 & 39 & 14 \\
\hline Centro Sul Baiano BA & 6,87 & 60,42 & 77 & 39 & 38 \\
\hline Noroeste Espírito-santense ES & 6,86 & 67,28 & 46 & 39 & 6 \\
\hline Vale do Rio Doce MG & 4,42 & 71,7 & 27 & 25 & 2 \\
\hline Litoral Norte Espírito-santense ES & 3,24 & 74,94 & 25 & 18 & 7 \\
\hline Norte Central Paranaense PR & 2,86 & 77,8 & 116 & 16 & 100 \\
\hline Norte Pioneiro Paranaense PR & 2,69 & 80,49 & 36 & 15 & 21 \\
\hline Oeste de Minas MG & 1,83 & 82,32 & 16 & 10 & 6 \\
\hline Campinas SP & 1,7 & 84,02 & 24 & 10 & 14 \\
\hline TriânguloMineiro/AltoParanaíbaMG & 1,61 & 85,63 & 53 & 9 & 44 \\
\hline Jequitinhonha MG & 1,39 & 87,02 & 9 & 8 & 1 \\
\hline Noroeste Paranaense PR & 1,16 & 88,18 & 7 & 7 & $\mathrm{O}$ \\
\hline Ribeirão Preto SP & 0,98 & 89,16 & 141 & 6 & 135 \\
\hline Madeira-Guaporé RO & 0,93 & 90,09 & $\mathrm{O}$ & 5 & -5 \\
\hline Presidente Prudente SP & 0,91 & 91 & 10 & 5 & 5 \\
\hline Noroeste Fluminense RJ & 0,79 & 91,79 & 5 & 4 & 1 \\
\hline Vale do Mucuri MG & 0,76 & 92,55 & 1 & 4 & -3 \\
\hline Centro Norte Baiano BA & 0,75 & 93,3 & 0 & 4 & -4 \\
\hline Campo das Vertentes MG & 0,67 & 93,97 & 3 & 4 & -1 \\
\hline Norte Mato-grossense MT & 0,64 & 94,61 & $\mathrm{O}$ & 4 & -4 \\
\hline Assis SP & 0,59 & 95,2 & 7 & 3 & 4 \\
\hline Sul Baiano BA & 0,58 & 95,78 & 5 & 3 & 2 \\
\hline Marília SP & 0,5 & 96,28 & 20 & 3 & 17 \\
\hline São José do Rio Preto SP & 0,48 & 96,76 & $\mathrm{O}$ & 3 & -3 \\
\hline Centro Ocidental Paranaense PR & 0,47 & 97,23 & 11 & 3 & 8 \\
\hline Bauru SP & 0,43 & 97,66 & 4 & 2 & 2 \\
\hline Norte de Minas MG & 0,35 & 98,01 & 4 & 2 & 2 \\
\hline Agreste Pernambucano PE & 0,27 & 98,28 & $\mathrm{O}$ & 2 & -2 \\
\hline Oeste Paranaense PR & 0,27 & 98,55 & $\mathrm{O}$ & 2 & -2 \\
\hline Araçatuba SP & 0,23 & 98,78 & 0 & 1 & -1 \\
\hline Metropolitana deBelo Horizonte MG & 0,12 & 98,9 & 1 & 1 & $\mathrm{O}$ \\
\hline Piracicaba SP & 0,12 & 99,02 & 2 & 1 & 1 \\
\hline SudoestedeMatoGrossodoSulMS & 0,11 & 99,13 & $\mathrm{O}$ & 1 & -1 \\
\hline Outras Mesorregiões & 0,87 & 100 & 20 & $\mathrm{O}$ & 20 \\
\hline Total & 100 & & 1136 & 569 & 573 \\
\hline
\end{tabular}

Fonte: Delineamento amostral do estudo. 
O levantamento de dados no Brasil todo foi realizado entre março de 2014 e maio de 2017. Foram avaliadas 1136 empresas cafeeiras, nos estados de Minas Gerais (472), Espírito Santo (175), São Paulo (211), Paraná (170), Bahia (91), Rondônia (08), Rio de Janeiro (07) e Distrito Federal (2). Essas empresas estão localizadas em 233 municípios, pertencentes a 80 microrregiões e 35 mesorregiões geográficas brasileiras. Desses totais, o Paraná contribuiu com 32 municípios em 12 microrregiões e quatro mesorregiões cafeeiras (Quadro 3).

Quadro 3 - Relação do número de amostras nos municípios e respectivas micro e mesorregiões geográficas cafeeiras analisados no Estado do Paraná

\begin{tabular}{|c|c|c|c|c|c|c|}
\hline Paraná & & Município & & crorregião & \multicolumn{2}{|c|}{ Mesorregião } \\
\hline $\begin{array}{c}\text { Número de } \\
\text { avaliações }\end{array}$ & Número & Nome & Número & Nome & Número & Nome \\
\hline $\begin{array}{l}7 \\
4\end{array}$ & $\begin{array}{l}1 \\
2\end{array}$ & $\begin{array}{c}\text { Araruna } \\
\text { Corumbataí do Sul }\end{array}$ & 1 & Campo Mourão & 1 & $\begin{array}{c}\text { Centro } \\
\text { Ocidental } \\
\text { Paranaense }\end{array}$ \\
\hline $\begin{array}{l}4 \\
2 \\
1\end{array}$ & $\begin{array}{l}3 \\
4 \\
5\end{array}$ & $\begin{array}{c}\text { Cianorte } \\
\text { São Tomé } \\
\text { São Jorge do }\end{array}$ & 2 & Cianorte & \multirow[t]{2}{*}{2} & \multirow[t]{2}{*}{$\begin{array}{c}\text { Noroeste } \\
\text { Paranaense } \\
\text { (o7 empresas) }\end{array}$} \\
\hline 1 & b & sau Jorge 40 & 3 & umuarama & & \\
\hline 23 & 6 & Apucarana & \multirow{5}{*}{4} & \multirow{5}{*}{ Apucarana } & \multirow{14}{*}{3} & \multirow{14}{*}{$\begin{array}{l}\text { Norte Central } \\
\text { Paranaense } \\
\text { (116 empresas) }\end{array}$} \\
\hline 1 & 7 & Arapongas & & & & \\
\hline 6 & 8 & Califórnia & & & & \\
\hline 8 & 9 & Jandaia do Sul & & & & \\
\hline 1 & 10 & Sabáudia & & & & \\
\hline 1 & 11 & Astorga & & Astor 9 . & & \\
\hline 1 & 12 & Santa Fé & 5 & Astoiga & & \\
\hline 30 & 13 & Grandes Rios & 6 & Ivaiporã & & \\
\hline 17 & 14 & & & & & \\
\hline 22 & 15 & Londrina & & & & \\
\hline 3 & 16 & Pitangueiras & 7 & I andring & & \\
\hline 1 & 17 & Rolândia & 7 & LOHInina & & \\
\hline 1 & 18 & Tamarana & & & & \\
\hline 1 & 19 & Maringá & 8 & Maringá & & \\
\hline 1 & 20 & Rancho Alegre & & & & \\
\hline 2 & 21 & N. Santa Bárbara & 9 & Assaí & & \\
\hline 6 & 22 & S. Jerônimo da & & & & \\
\hline 1 & 23 & Congonhinhas & & & & \\
\hline 1 & 24 & Nova Fátima & & & & \\
\hline 1 & 25 & Ribeirão Claro & 10 & $\begin{array}{l}\text { Cornélio } \\
\text { Procópio }\end{array}$ & & Norte Pioneiro \\
\hline 1 & 26 & Ribeirão do Pinhal & & & 4 & Paranaense \\
\hline 2 & 27 & Santa Mariana & & & & (36 empresas) \\
\hline 1 & 28 & Japira & 11 & Thait & & \\
\hline 9 & 29 & Pinhalão & 11 & IDaltı & & \\
\hline 1 & 30 & Carlópolis & & & & \\
\hline 2 & 31 & Joaquim Távora & 12 & Wenceslau Braz & & \\
\hline 8 & 32 & Tomazina & & & & \\
\hline 170 & 32 & Total de municípios & 12 & $\begin{array}{c}\text { Total de } \\
\text { microrregiões }\end{array}$ & 4 & $\begin{array}{c}\text { Total de } \\
\text { mesorregiões }\end{array}$ \\
\hline
\end{tabular}

Fonte: Amostragem do estudo. 


\section{Classificação do porte das empresas}

Adotou-se a classificação de tamanho de propriedade rural do Instituto Nacional de Colonização e Reforma Agrária (INCRA, 2017), que leva em conta o Módulo Fiscal, que varia de 5 a 110 hectares, de acordo com o município onde a propriedade se localiza. Sua vantagem é a de utilizar informações que os empresários rurais não consideram tão confidenciais quanto àquelas solicitadas em outras classificações. E compreende as seguintes categorias de imóveis rurais:

- Minifúndio: área inferior a 1 (um) módulo fiscal;

- Pequena Propriedade: área entre 1 (um) e 4 (quatro) módulos fiscais;

- Média Propriedade: área superior a 4 (quatro) e até 15 (quinze) módulos fiscais; e

- Grande Propriedade: imóvel rural de área superior 15 (quinze) módulos fiscais.

\section{Análise fatorial}

De acordo com Hair Júnior et al. (2009), alguns dos critérios para definição do número de fatores a serem extraídos são o percentual da variância, a raiz latente, o teste scree e a heterogeneidade dos respondentes. Seu objetivo é garantir significância prática aos fatores extraídos, visando garantir que expliquem grande parte da variância total dos dados. Segundo esse autor, em ciências naturais obtêm-se fatores que expliquem ao menos $95 \%$ da variância. Nas ciências sociais, onde as informações geralmente são menos precisas, uma solução que explique $60 \%$ da variância total, e em alguns casos até menos, pode ser satisfatória. Neste estudo utilizou-se o Critério da Raiz Latente (fatores com autovalores acima de 1,0). A significância das cargas fatoriais foi determinada de acordo com o tamanho amostral (Quadro 4). As análises foram realizadas diversas vezes, excluindo-se as variáveis não significativas, até estabilização, por meio do programa IBM SPSS Statistics.

Quadro 4. Tamanho amostral para referência da significância das cargas fatoriais

\begin{tabular}{|c|c|c|c|}
\hline Carga Fatorial & Tamanho da amostra & Carga Fatorial & Tamanho da amostra \\
\hline 0,3 & 350 & 0,55 & 100 \\
\hline 0,35 & 250 & 0,6 & 85 \\
\hline 0,4 & 200 & 0,65 & 70 \\
\hline 0,45 & 150 & 0,70 & 60 \\
\hline 0,5 & 120 & 0,75 & 50 \\
\hline
\end{tabular}

Fonte: Hair Júnior. et al. (2009).

\section{Resultados}

Primeiramente é apresentada uma caracterização das empresas cafeeiras analisadas no estado do Paraná, de acordo com a adoção de certificações agrícolas, tamanho dos imóveis rurais, área cultivada com café, outras atividades agropecuárias desenvolvidas na empresa e número de colaboradores fixos. Observou-se que aquelas empresas utilizam principalmente mão de obra familiar e produzem exclusivamente café arábica. Raras lavouras de café robusta podem ser encontradas e se destinam à produção de sementes de porta-enxerto para o café arábica em algumas regiões com solos infectados com nematóides.

Quanto às certificações agrícolas, das 170 empresas avaliadas, apenas 14 são certificadas: duas no Norte Central - Utz Certified (o1), Cercamento (o1); 12 no Norte 
Pioneiro, todas Fairtrade (comércio justo). Com relação às atividades desenvolvidas nas empresas, das 170 empresas, 54 produzem apenas café arábica (ou café e reflorestamento) como atividade econômica. Outras 28 trabalham com café arábica (ou reflorestamento) e pecuária. Vinte empresas trabalham com café arábica (e reflorestamento) e olericultura (independente de trabalharem também com pecuária). A configuração "produção de café e olericultura" (comercial) se destacou no estado do Paraná. Nos demais estados a olericultura ocorre principalmente para consumo próprio. As demais 68 empresas trabalham com café arábica e outras lavouras que não olericultura (independentemente de pecuária ou reflorestamento).

A Tabela 1 mostra a classificação de tamanho das empresas avaliadas, de acordo com a classificação do INCRA. Observa-se que os minifúndios representam $92 \%$ da amostra.

Tabela 1 - Distribuição de tamanho das empresas cafeeiras avaliadas no Estado do Paraná, por mesorregião geográfica, classificadas em minifúndios, pequenos, médios e grandes imóveis rurais*

\begin{tabular}{|l|c|c|c|c|c|}
\hline \multirow{2}{*}{$\begin{array}{c}\text { Tamanho das } \\
\text { empresas }\end{array}$} & \multicolumn{5}{|c|}{ Número de empresas cafeeiras avaliadas } \\
\cline { 2 - 6 } & Paraná & \multicolumn{4}{|c|}{ Mesorregiões geográficas } \\
\cline { 2 - 6 } & & Norte Pioneiro & Norte Central & Centro Ocidental & Noroeste \\
\hline Minifúndios & 156 & 35 & 106 & 11 & 4 \\
\hline Pequenas & 12 & 0 & 9 & 0 & 3 \\
\hline Médias & 1 & 1 & 0 & 0 & 0 \\
\hline Grandes & 1 & 0 & 1 & 11 & 7 \\
\hline Total de empresas & 170 & 36 & 116 & 11 & o \\
\hline
\end{tabular}

* De acordo com a classificação do INCRA (2017).

Fonte: Resultados do estudo.

A área média total das 170 empresas avaliadas no estado do Paraná é 39,6 ha e a área média de cultivo de café nessas empresas é 10,6 ha (Tabela 2). Daquelas empresas, 95 (55,9\%) possuem menos de 5 ha de área cultivada com café, 154 (90,6\%) possuem até 15 ha de área com café e apenas $58(34,1 \%)$ possuem mais de 15 ha de área total.

Tabela 2 - Distribuição das empresas cafeeiras avaliadas no Estado do Paraná de acordo com suas respectivas áreas em hectares (ha)

\begin{tabular}{|l|c|c|c|c|}
\hline \multirow{2}{*}{ Classes de área } & \multicolumn{2}{|c|}{ Área total } & \multicolumn{2}{c|}{ Área café } \\
\cline { 2 - 5 } & Número de empresas & $\%$ & Número de empresas & $\%$ \\
\hline$\leq 5$ & 40 & 23,5 & 95 & 55,9 \\
\hline$(5-10]$ & 36 & 21,2 & 47 & 27,6 \\
\hline$(10-15]$ & 36 & 21,2 & 12 & 7,1 \\
\hline$(15-20]$ & 13 & 7,6 & 6 & 3,5 \\
\hline$(20-25]$ & 18 & 10,6 & 4 & 2,4 \\
\hline$(25-30]$ & 8 & 4,7 & 4 & 2,4 \\
\hline$(30-50]$ & 10 & 5,9 & 0 & 0,0 \\
\hline$>50$ & 9 & 5,3 & 2 & 1,2 \\
\hline Total & 170 & 100,0 & 170 & 100,0 \\
\hline
\end{tabular}

Fonte: Resultados do estudo.

Das 170 empresas, em 39 (22,9\%) o cafeicultor não conta com colaboradores fixos. Em 54 (31,7\%) contam com menos de dois colaboradores fixos. Portanto ao menos 92 empresas, ou 54,7\% da amostra, caracterizam-se como unidades de produção familiar. Esse número pode ser maior, pois pelo que determina a Lei da Agricultura Familiar (AF), a mão de obra familiar deve ser predominante no 
estabelecimento. Isso é, mesmo que com mais de 2 empregados, pode ser caracterizado como $\mathrm{AF}$ se dispor de 3 pessoas na família.

Foi realizado um estudo descritivo da amostra, com o cálculo de medidas de posição e dispersão: média, mediana, variância, desvio padrão e coeficiente de variação $-C v$, que analisa a dispersão em termos relativos, logo expresso em porcentagem (\%) e fornece a variação dos dados em relação à média. Utilizou-se o seguinte critério (PIMENTEL GOMES, 2009):

$$
C_{v}=\frac{s}{\dot{X}}
$$

Em que: $C_{v}=$ Coeficiente de variação, $\mathrm{s}=$ desvio padrão, $X$ = média.

- $C v \leq 10 \%$ - Baixa dispersão dos dados (amostra homogênea)

- $10 \%<C v \leq 20 \%$ - Média dispersão dos dados

- $20 \%<C v \leq 30 \%$ - Alta dispersão dos dados

- $C v>30 \%$ - Dispersão dos dados muito alta (amostra heterogênea)

\section{Mapeamento do grau de gestão no estado do Paraná}

Os graus de gestão das empresas cafeeiras do estado do Paraná são apresentados nas tabelas 3 a 6. O "Norte Central" foi a mesorregião com maior variabilidade nos dados e maior número de empresas avaliadas (116), o valor da média é superior à média do estado e o da mediana é igual ao valor do estado. O "Norte Pioneiro", onde foram avaliadas 36 empresas, apresentou média pouco superior àquela obtida para o estado e com variabilidade superior.

A mesorregião com menor variabilidade nos dados e maiores valores de média e mediana do Estado foi a "Noroeste", onde foram avaliadas sete empresas (Tabela 3). Apesar da amostra relativamente pequena, ela atende à estimativa para estratificação. A produção de café no "Noroeste" do Paraná se reduziu muito nos últimos anos e, segundo os técnicos entrevistados, os cafeicultores que persistiram na região são aqueles mais organizados e com melhor nível tecnológico. A maior parte dos cafeicultores que possuíam lavouras com baixas produtividades abandonaram a produção de café ou até mesmo as atividades agrícolas. Portanto, os valores mais elevados observados no "Noroeste" podem resultar da seleção ocorrida entre os produtores da mesorregião e não da dimensão da amostra.

A mesorregião "Centro Ocidental" apresentou a menor média do estado e grande variabilidade. A amostra avaliada - 11 empresas - atende à estimativa para estratificação. As mesorregiões "Norte Pioneiro" e "Norte Central" concentram o maior volume de café produzido no estado. Ambas apresentam grau de gestão com mediana 6,0 e as demais medidas de dispersão são muito próximas. A mesorregião "Centro Ocidental" apresentou a menor média do estado do Paraná $(5,6)$. (Tabela 3).

Tabela 3 - Dispersão do grau de gestão na produção cafeeira nas mesorregiões geográficas do Estado do Paraná

\begin{tabular}{|c|c|c|c|c|c|c|}
\hline \multirow[b]{2}{*}{$\begin{array}{l}\text { Dispersão do grau de gestão } \\
\text { na produção cafeeira }\end{array}$} & \multicolumn{4}{|c|}{ Mesorregiões geográficas } & \multirow[b]{2}{*}{ Paraná } & \multirow[b]{2}{*}{ Brasil } \\
\hline & $\begin{array}{c}\text { Norte } \\
\text { Pioneiro } \\
\end{array}$ & $\begin{array}{c}\text { Norte } \\
\text { Central } \\
\end{array}$ & $\begin{array}{c}\text { Centro } \\
\text { Ocidental }\end{array}$ & Noroeste & & \\
\hline Média & 6,2 & 6,2 & 5,6 & 6,8 & 6,2 & 6,6 \\
\hline Mediana & 6,0 & 6,0 & 6,0 & 7,0 & 6,0 & 7,0 \\
\hline Variância & 3,0 & 3,4 & 2,7 & 2,1 & 3,2 & 3,4 \\
\hline Desvio padrão & 1,8 & 1,9 & 1,6 & 1,4 & 1,8 & 1,8 \\
\hline Coeficientedevariação(\%) & 28,4 & 29,7 & 28,9 & 21,3 & 20,0 & 27,9 \\
\hline Número de empresas & 36 & 116 & 11 & 7 & 170 & 1136 \\
\hline
\end{tabular}

Fonte: Resultados do estudo. 
$\mathrm{Na}$ mesorregião "Norte Central", onde se localizam $68,2 \%$ das empresas avaliadas no Estado, as médias de gestão variam de 5,8 na microrregião de Apucarana a 6,5 na microrregião de Ivaiporã. Londrina é a microrregião com maior heterogeneidade amostral e maior variabilidade no nível de gestão das empresas em relação à média (Tabela 4).

Tabela 4 - Dispersão do grau de gestão na produção cafeeira, microrregiões geográficas da mesorregião Norte Central do Estado do Paraná

\begin{tabular}{|c|c|c|c|c|c|c|}
\hline \multirow{3}{*}{$\begin{array}{l}\text { Dispersão do grau de } \\
\text { gestão na produção } \\
\text { cafeeira }\end{array}$} & \multicolumn{4}{|c|}{ Mesorregião geográfica Norte Central do Paraná } & \multirow{3}{*}{ Paraná } & \multirow{3}{*}{ Brasil } \\
\hline & \multicolumn{3}{|c|}{ Microrregiões } & \multirow{2}{*}{ Mesorregião } & & \\
\hline & Apucarana & Ivaiporã & Londrina & & & \\
\hline Média & 5,8 & 6,5 & 5,9 & 6,2 & 6,2 & 6,6 \\
\hline Mediana & 6,0 & 7,0 & 6,0 & 6,0 & 6,0 & 7,0 \\
\hline Variância & 3,0 & 3,1 & 4,2 & 3,4 & 3,2 & 3,4 \\
\hline Desvio padrão & 1,7 & 1,8 & 2,0 & 1,9 & 1,8 & 1,8 \\
\hline Coeficientedevariação(\%) & 30,1 & 26,9 & 34,4 & 29,7 & 20,0 & 27,9 \\
\hline Número de empresas & 24 & 47 & 24 & 116 & 170 & 1136 \\
\hline
\end{tabular}

Fonte: Resultados do estudo.

No "Norte Pioneiro", com 21,2\% da amostra, a média de gestão varia de 5,5 na microrregião de Wenceslau Braz a 7,0 em Cornélio Procópio (Tabela 5). A microrregião de Assaí apresenta a maior heterogeneidade amostral e Ibaiti a menor.

Tabela 5 - Dispersão do grau de gestão na produção cafeeira, microrregiões geográficas da mesorregião Norte Pioneiro do Estado do Paraná

\begin{tabular}{|c|c|c|c|c|c|c|c|}
\hline \multirow{3}{*}{$\begin{array}{l}\text { Dispersão do grau de } \\
\text { gestão na produção } \\
\text { cafeeira }\end{array}$} & \multicolumn{5}{|c|}{ Mesorregião geográfica Norte Pioneiro do Paraná } & \multirow{3}{*}{ Paraná } & \multirow{3}{*}{ Brasil } \\
\hline & \multicolumn{4}{|c|}{ Microrregiões } & \multirow{2}{*}{ Mesorregião } & & \\
\hline & Assaí & $\begin{array}{l}\text { Cornélio } \\
\text { Procópio }\end{array}$ & Ibaiti & $\begin{array}{c}\text { Wenceslau } \\
\text { Braz }\end{array}$ & & & \\
\hline Média & 6,7 & 7,0 & 5,9 & 5,6 & 6,2 & 6,2 & 6,6 \\
\hline Mediana & 7,0 & 7,0 & 6,0 & 5,6 & 6,0 & 6,0 & 7,0 \\
\hline Variância & 4,5 & 3,6 & 1,4 & 2,8 & 3,0 & 3,2 & 3,4 \\
\hline Desvio padrão & 2,1 & 1,9 & 1,2 & 1,7 & 1,8 & 1,8 & 1,8 \\
\hline Coeficientedevariação(\%) & 38,2 & 27,1 & 20,3 & 30,5 & 28,4 & 20,0 & 27,9 \\
\hline Número de empresas & 9 & 6 & 10 & 11 & 36 & 170 & 1136 \\
\hline
\end{tabular}

Fonte: Resultados do estudo.

O município de Grandes Rios, microrregião de Ivaiporã, no "Norte Central”, com $17,7 \%$ da amostra, apresenta os níveis de gestão mais uniformes (Tabela 6). 
Tabela 6 - Dispersão do grau de gestão na produção cafeeira, municípios de Grandes Rios, Ivaiporã e Londrina, microrregiões Ivaiporã e Londrina, mesorregião Norte Central do Paraná

\begin{tabular}{|c|c|c|c|c|c|c|c|c|}
\hline \multirow{3}{*}{$\begin{array}{l}\text { Dispersão do } \\
\text { grau de gestão } \\
\text { na produção } \\
\text { cafeeira }\end{array}$} & \multicolumn{3}{|c|}{ Microrregião Ivaiporã } & \multicolumn{2}{|c|}{ Microrregião Londrina } & \multirow{3}{*}{$\begin{array}{l}\text { Mesorregião } \\
\text { NorteCentral }\end{array}$} & \multirow{3}{*}{ Paraná } & \multirow{3}{*}{ Brasil } \\
\hline & \multicolumn{2}{|c|}{ Municípios } & \multirow[b]{2}{*}{ Microrregião } & Município & & & & \\
\hline & $\begin{array}{c}\text { Grandes } \\
\text { Rios }\end{array}$ & Ivaiporã & & Londrina & Microrregião & & & \\
\hline Média & 6,9 & 5,8 & 6,5 & 5,7 & 5,7 & 6,2 & 6,2 & 6,6 \\
\hline Mediana & 7,0 & 6,0 & 7,0 & 6,0 & 6,0 & 6,0 & 6,0 & 7,0 \\
\hline Variância & 2,1 & 4,2 & 3,1 & 3,4 & 3,4 & 3,4 & 3,2 & 3,4 \\
\hline Desviopadrão & 1,5 & 2,0 & 1,8 & 1,8 & 1,8 & 1,9 & 1,8 & 1,8 \\
\hline $\begin{array}{l}\text { Coeficiente } \\
\text { variacão (\%) }\end{array}$ & 21,3 & 35,00 & 27,00 & 32,0 & 32,0 & 29,7 & 20,0 & 27,9 \\
\hline $\begin{array}{l}\text { Número de } \\
\text { empresas }\end{array}$ & 30 & 17 & 47 & 22 & 22 & 116 & 170 & 1136 \\
\hline
\end{tabular}

Fonte: Resultados do estudo.

Quanto às pontuações obtidas nas avaliações, para cada critério de gestão, as 170 empresas foram subdivididas em três categorias (Tabela 7), de acordo com o porcentual alcançado em relação à pontuação máxima possível em cada critério:

- Alta: número de empresas com pontuação acima de 70\% da máxima possível.

- Média: número de empresas com pontuação entre 40\% e 70\% da máxima.

- Baixa: número de empresas com pontuação inferior a 40\% da máxima.

Os indicadores que compõem o critério "Planejamento e estratégias" estão entre os principais pontos fracos no sistema de gestão das empresas cafeeiras no Paraná, isto é, entre os indicadores com menores níveis de adoção.

Há 24 indicadores direta ou indiretamente vinculados à SST, que estão destacados com fundo cinza na Tabela 7. Os valores de seis deles são superiores às médias para o Brasil, 17 deles alcançaram mínimo de 60,0\% de adoção e seis alcançaram nível igual ou superior a 90\% de adoção.

Quanto ao uso de E.P.Is, indicador 28, a simples disponibilização de equipamentos não garante que seu uso entre os trabalhadores seja efetivo e correto, conforme destacado no indicador, portanto o valor observado pode estar superestimado. O indicador 29, oferta de plano de saúde aos colaboradores, é um benefício também para a empresa, pois pode reduzir os afastamentos por problemas de saúde, é aquele com menor nível de atendimento, tanto para o estado como para o Brasil. $\mathrm{O}$ indicador 18, "a organização sempre contrata funcionários com idade igual ou superior àquela estabelecida na legislação", tem média de adoção brasileira de 87,0\% e de 76,5\% no Paraná. Os empresários rurais seguem a legislação e entendem a necessidade dos menores receberem educação básica formal, mas consideram sua participação como aprendizes, em tarefas não estafantes, fundamental para forjar aptidões agrícolas, dificilmente assimiladas em idade mais avançada, e imprescindível para garantir que parte da população permaneça na atividade agrícola, além de ser importante, em muitos casos, na sucessão familiar.

Quanto à busca por informações e conhecimentos, os índices de adoção são relativamente elevados - a participação de representante da empresa em eventos técnicos chega a 95,9\% - porém o acesso à internet ainda é baixo.

Liderança é o critério de gestão com percentual mais elevado de adoção entre as empresas; nesse critério, 124 empresas (73,0\% da amostra) alcançaram pontuação superior a 70,0\% da pontuação máxima possível para o critério. 
Sociedade é o segundo critério com maior percentual de adoção; 102 empresas (60,0\% da amostra) alcançaram 70,0\% da pontuação máxima possível.

Não foram observadas diferenças significativas entre os níveis de gestão das empresas cafeeiras nas mesorregiões do estado do Paraná. Entre as microrregiões os níveis médios de gestão variaram de 5,6 no Centro Ocidental a 6,8 no Noroeste.

Tabela 7 - Estado do Paraná, proporção de empresas da amostra segundo três categorias de pontuação: inferior a 40\% da pontuação máxima, entre 40 e 70\% da máxima e superior a 70\% da máxima, por critério avaliado

\begin{tabular}{|c|c|c|c|c|c|c|c|}
\hline \multirow{3}{*}{ Critério } & \multirow{3}{*}{$\begin{array}{l}\text { Pontuação } \\
\text { máxima }\end{array}$} & \multicolumn{2}{|c|}{ Alta pontuação } & \multicolumn{2}{|c|}{ Média pontuação } & \multicolumn{2}{|c|}{ Baixa pontuação } \\
\hline & & \multicolumn{2}{|c|}{ >70\% da máxima } & \multicolumn{2}{|c|}{$\geq 40$ e $<70 \%$ da máxima } & \multicolumn{2}{|c|}{$<40 \%$ da máxima } \\
\hline & & No-empresas & $\%$ & No-empresas & $\%$ & No-empresas & $\%$ \\
\hline Planejamento & 60 & 11 & 6,5 & 27 & 15,9 & 132 & 77,7 \\
\hline Liderança & 50 & 124 & 72,9 & 29 & 17,0 & 17 & 10,0 \\
\hline Clientes & 90 & 50 & 29,4 & 66 & 38,8 & 54 & 31,8 \\
\hline Sociedade & 60 & 102 & 60,0 & 57 & 33,5 & 11 & 6,5 \\
\hline Informações & 90 & 86 & 50,6 & 64 & 37,7 & 20 & 11,8 \\
\hline Pessoas & 60 & 56 & 32,9 & 61 & 35,9 & 53 & 31,2 \\
\hline Processos & 190 & 79 & 46,5 & 76 & 44,8 & 15 & 8,8 \\
\hline Resultados & 400 & 68 & 40,0 & 71 & 41,8 & 31 & 18,2 \\
\hline Pontuação & 1000 & 61 & 35,9 & 87 & 51,2 & 22 & 12,9 \\
\hline
\end{tabular}

Fonte: Resultados do estudo.

A média do Estado se mostrou pouco inferior à média brasileira, porém significativamente inferior à média do estado de São Paulo (Tabela 8).

Tabela 8 - Níveis médios de gestão nas empresas cafeeiras brasileiras, por estado

\begin{tabular}{|l|c|c|}
\hline \multicolumn{1}{|c|}{ Estado produtor } & Número de empresas avaliadas & Níveis médios de gestão \\
\hline Minas Gerais & 472 & 6,6 \\
\hline Espírito Santo & 175 & 6,2 \\
\hline São Paulo & 211 & $\mathbf{7 , 5}$ \\
\hline Bahia & 91 & 5,6 \\
\hline Paraná & 170 & 6,2 \\
\hline Outros & 17 & 7,0 \\
\hline Total Brasil & 1136 & 6,6 \\
\hline
\end{tabular}

Fonte: Resultados do estudo.

$\mathrm{Na}$ Tabela 9 são apresentados os percentuais médios de adoção dos 64 indicadores de gestão avaliados para o estado do Paraná e para o Brasil. 
Tabela 9 - Percentual médio de adoção dos 64 indicadores de gestão, estado do Paraná (170 empresas) em ordem decrescente de adoção e respectivos valores para o Brasil (1136 empresas)

\begin{tabular}{|c|c|c|c|c|c|}
\hline \multirow{2}{*}{ Indicadores (sintetizados) } & PR & $\mathrm{BR}$ & \multirow{2}{*}{ Indicadores (sintetizados) } & PR & $\overline{B R}$ \\
\hline & \multicolumn{2}{|c|}{$\%$} & & \multicolumn{2}{|r|}{ שת } \\
\hline 24 - Participação em eventos. & 95,9 & 85,7 & o6-Solução de atritos. & 64,7 & 86,4 \\
\hline 58 - Regulamentações ambientais. & 94,1 & 86,7 & 59-Satisfação dos colaboradores. & 64,7 & 68,4 \\
\hline 22 - Assistência pública e privada. & 92,9 & 89,6 & 63 - Relacionamento com clientes. & 64,1 & 75,7 \\
\hline 39- Orientação para colheita. & 92,4 & 96,2 & 30 - Formação dos colaboradores. & 62,4 & 65,1 \\
\hline o5 - Administração justa. & 90,0 & 96,1 & 15-Falhas de entregas. & 61,8 & 75,4 \\
\hline 44 - Armazenamento do café. & 90,0 & 90,9 & 31 - Liderança de colaboradores. & 61,2 & 72,3 \\
\hline 17- Descarte de água e resíduos. & 89,4 & 90,0 & 33 - Remuneração de colaboradores. & 60,6 & 69,8 \\
\hline 37-Controle nutricional regular. & 87,1 & 88,7 & 6o - Melhoria da produtividade. & 60,0 & 54,4 \\
\hline 41 - Transporte de grãos. & 82,9 & 80,6 & 11 - Avaliação de produtos. & 59,4 & 70,5 \\
\hline 20 - Taxas e impostos em ordem. & 82,4 & 87,6 & 14 - Internalização das reclamações. & 58,8 & 70,9 \\
\hline 42- Unidade de pós-colheita. & 81,2 & 80,4 & 45 - Parâmetros de armazenagem. & 55,9 & 68,3 \\
\hline o8 - Fatores de produção. & 80,0 & 85,5 & 47- Manutenção preventiva. & 55,9 & 68,3 \\
\hline 19 - Cooperativismo. & 80,0 & 74,9 & 21 - Ética assegurada. & 55,3 & 46,4 \\
\hline o9 - Delegação de atividades. & 79,4 & 91,5 & 46 - Inspeções de qualidade. & 54,7 & 57,5 \\
\hline 64 - Relação com fornecedores. & 79,4 & 85,9 & 49 - Controle da qualidade. & 54,7 & 50,1 \\
\hline 12 - Telefone disponível. & 78,8 & 86,0 & 56 - Relacionamento com o mercado. & 54,1 & 52,8 \\
\hline 57 - Reconhecimento da empresa. & 77,6 & 75,7 & 55 - Satisfação dos clientes diretos. & 52,9 & 53,7 \\
\hline 40 - Colheita em contato com solo. & 77,1 & 93,5 & 10 - Definição de valores de venda. & 51,8 & 66,6 \\
\hline 51 - Crédito agrícola. & 77,1 & 75,4 & 50 - Histórico dos volumes colhidos. & 51,8 & 60,2 \\
\hline 18 - Idade mínima de trabalho. & 76,5 & 87,0 & 61 - Classificação de grãos. & 50,6 & 55,1 \\
\hline 48 - Organização e limpeza. & 75,9 & 77,7 & 23 - Uso da internet. & 50,0 & 60,9 \\
\hline 25 - Relacionamento com clientes. & 75,3 & 79,5 & 43-Controle de secagem. & 50,0 & 68,0 \\
\hline o7-Comunicação com colaboradores. & 74,7 & 80,8 & 27 - Registros e protocolos. & 48,2 & 43,8 \\
\hline 32 - Desempenho de colaboradores & 72,4 & 77,3 & 52 - Seguro agrícola. & 42,4 & 53,1 \\
\hline 53 - Acompanhamento das vendas. & 71,8 & 75,1 & 62 - Avaliação da eficiência. & 42,4 & 44,2 \\
\hline 34 - Material genético aprimorado. & 71,2 & 64,5 & 04 - Índices de ajuste. & 37,1 & 47,9 \\
\hline 26 - Novos nichos de mercados. & 70,6 & 73,8 & 38 - Uso de tecnologia no manejo. & 35,9 & 37,7 \\
\hline 36 - Mudas e sementes certificadas. & 70,6 & 70,7 & 13 - Histórico de clientes. & 30,6 & 51,6 \\
\hline 28 - Uso regular de E.P.I. & 68,2 & 77,8 & o3 - Planejamento, etapas, metas. & 21,2 & 34,0 \\
\hline 35 - Uso e teste de variedades. & 68,2 & 47,7 & 02 - Missão, Visão, Valores. & 10,0 & 13,2 \\
\hline 54 - Avaliação da receita. & 68,2 & 74,5 & o1 - Estratégias e planos. & 7,6 & 13,1 \\
\hline $\begin{array}{r}16 \text { - Uso racional de agroquímicos. } \\
\text { Osindicadores destaca }\end{array}$ & 66,5 & & $\begin{array}{l}\text { 29-Planodesaúdeaos colaboradores. } \\
\text { liretamenterelacionadosà SegurançaeS }\end{array}$ & $\begin{array}{c}7,6 \\
\text { Trabal } \\
\end{array}$ & $\begin{array}{r}8,4 \\
\text { SST) } \\
\end{array}$ \\
\hline
\end{tabular}

Fonte: Resultados do estudo. 


\section{Análise fatorial}

Iniciou-se a análise fatorial com 64 variáveis, correspondentes aos indicadores do MIGG Café Ao longo do processo excluíram-se 20 variáveis, consideradas não significativas. Foram obtidos 14 fatores - componentes principais - que explicam 66,8\% da variância da amostra (Tabela 10). 
Tabela 10 - Indicadores de gestão, Fatores 1 a 14, Estado do Paraná, 170 propriedades, ordenados da maior para a menor carga fatorial, correlação amostral acima de 0,512

\begin{tabular}{|c|c|c|c|c|c|}
\hline Fator & \multicolumn{5}{|c|}{ Variáveis que compõem o fator e respectivas correlações amostrais } \\
\hline $\begin{array}{l}\text { 1. Gestãoderecursos } \\
\text { humanos }\end{array}$ & $\begin{array}{c}\text { 32. Desempenhode } \\
\text { colaboradores } \\
\text {,755 } \\
\end{array}$ & $\begin{array}{c}\text { 33. Remuneraçãode } \\
\text { colaboradores } \\
, 742 \\
\end{array}$ & $\begin{array}{c}\text { 31. Lideranca entre } \\
\text { colaboradores } \\
, 724 \\
\end{array}$ & \begin{tabular}{|c|}
$\begin{array}{c}\text { 59. Bem-estardos } \\
\text { colaboradores } \\
537\end{array}$ \\
\end{tabular} & \\
\hline 2. Liderança & $\begin{array}{c}\text { 05. Administração } \\
\text { justa } \\
\text {,739 }\end{array}$ & $\begin{array}{l}\text { 06. Solução deatritos } \\
\text {,659 }\end{array}$ & $\begin{array}{l}\text { o8.Informaçōes } \\
\text { sobrefatoresde } \\
\text { produção } \\
, 656 \\
\end{array}$ & $\begin{array}{c}\text { o9.Obrigacõose } \\
\text { responsabilidades } \\
, 650\end{array}$ & \begin{tabular}{|c|} 
07. \\
Comunicação \\
naempresa \\
, 598 \\
\end{tabular} \\
\hline 3. Comercial & $\begin{array}{c}\text { 10. Definição de } \\
\text { valores devenda } \\
, 631\end{array}$ & $\begin{array}{l}\text { 11. Avaliação regularde } \\
\text { produtos } \\
, 615\end{array}$ & $\begin{array}{c}\text { 26. Novas } \\
\text { oportunidadesde } \\
\text { comercialização } \\
\text {,607 }\end{array}$ & $\begin{array}{c}\text { 61. Percentualde } \\
\text { grãosporclassesde } \\
\text { padrão } \\
, 547 \\
\end{array}$ & $\begin{array}{c}\text { 27. Protocolos } \\
\text { detecnologias } \\
\text { eprocessos } \\
526 \\
5\end{array}$ \\
\hline $\begin{array}{l}\text { 4.Controlede } \\
\text { qualidadepós-colheita }\end{array}$ & $\begin{array}{l}\text { 43. Avalição dos } \\
\text { parâmetros de } \\
\text { secagem } \\
, 792 \\
\end{array}$ & $\begin{array}{c}\text { 45. Avaliação do } \\
\text { produtoarmazenado } \\
, 792\end{array}$ & $\begin{array}{l}\text { 46. Inspecõesde } \\
\text { controlede } \\
\text { qualidade } \\
, 792 \\
\end{array}$ & & \\
\hline 5. Eficiência produtiva & $\begin{array}{c}\text { 54. Evolução dareceita } \\
720\end{array}$ & $\begin{array}{c}\text { 60.Avaliaçãoda } \\
\text { produtividade } \\
.587\end{array}$ & $\begin{array}{c}\text { 62. Eficiência } \\
\text { operacional } \\
560 \\
\end{array}$ & & \\
\hline $\begin{array}{l}\text { 6. Relacionamento } \\
\text { comfornecedores }\end{array}$ & $\begin{array}{c}\text { 64. Acôescorretivas } \\
\text { dosfornecedores } \\
, 762\end{array}$ & $\begin{array}{c}\text { 63. Qualidadedos } \\
\text { serviçosrecebidos } \\
, 720\end{array}$ & & & \\
\hline $\begin{array}{l}\text { 7. Relacionamento } \\
\text { comclientes }\end{array}$ & $\begin{array}{l}\text { 15. Soluçãodefalhas } \\
\text { deentregas } \\
, 830 \\
\end{array}$ & $\begin{array}{c}\text { 14. Reclamaçoesdos } \\
\text { clientes } \\
, 756 \\
\end{array}$ & & & \\
\hline 8. Planejamento & $\begin{array}{c}\text { O1. PlanodeNegócio } \\
, 798\end{array}$ & $\begin{array}{l}\text { O3. Planejamento } \\
\text {,774 }\end{array}$ & & & \\
\hline $\begin{array}{l}\text { 9. Informações } \\
\text { externas }\end{array}$ & $\begin{array}{c}\text { 22. Uso de } \\
\text { assistência técnica } \\
, 750\end{array}$ & $\begin{array}{l}\text { 25. Contato regular } \\
\text { com clientes } \\
, 512 \\
\end{array}$ & & & \\
\hline $\begin{array}{l}\text { 10. Segurança no } \\
\text { trabalho }\end{array}$ & $\begin{array}{c}\text { 28. Uso regular e } \\
\text { correto de E.P.I. } \\
, 739\end{array}$ & & & & \\
\hline \begin{tabular}{|c|} 
11. Armazenagem \\
de produtose \\
capacitação de \\
colaboradores
\end{tabular} & $\begin{array}{c}44 . \\
\text { Armazenamento } \\
\text { adequado do café } \\
, 723 \\
\end{array}$ & $\begin{array}{c}\text { 30. Formação e } \\
\text { treinamento de } \\
\text { colaboradores } \\
, 512 \\
\end{array}$ & & & \\
\hline \begin{tabular}{|c|} 
12. Unidade de pós- \\
colheita e \\
reputação da \\
empresa \\
\end{tabular} & $\begin{array}{c}\text { 42. Unidade de pós- } \\
\text { colheita adequada } \\
, 711\end{array}$ & $\begin{array}{c}\text { 57. Reputação da } \\
\text { empresa } \\
, 617\end{array}$ & & & \\
\hline $\begin{array}{l}\text { 13. Colheita e } \\
\text { transporte dos } \\
\text { grãos }\end{array}$ & $\begin{array}{c}\text { 40. Colheita de } \\
\text { grãos sem contato } \\
\text { com solo } \\
, 828 \\
\end{array}$ & $\begin{array}{c}\text { 41. Transporte } \\
\text { adequado dos grãos } \\
\text { colhidos } \\
, 532 \\
\end{array}$ & & & \\
\hline 14. Legislação & $\begin{array}{c}\text { 18. Idade mínima } \\
\text { de colaboradores } \\
, 715 \\
\end{array}$ & $\begin{array}{l}\text { 16. Uso racional de } \\
\text { agroquímicos } \\
, 543 \\
\end{array}$ & & & \\
\hline
\end{tabular}

Fonte: Resultados do estudo.

No primeiro fator (que explica 17,9\% da variância amostral) se destacam quatro indicadores vinculados à gestão de recursos humanos (critérios Pessoas e Resultados), que examinam o desenvolvimento dos colaboradores e os esforços para criar e manter um ambiente de trabalho e um clima organizacional que conduza à excelência do desempenho, à plena participação e ao crescimento das pessoas. O segundo fator (explica 7,5\% da variância) examina o sistema de liderança e o comprometimento pessoal da direção da empresa; se destacam os cinco indicadores do critério Liderança. O terceiro fator (explica $5,6 \%$ da variância) examina como as empresas segmentam seus produtos e o mercado, como fazem a gestão dos ativos intangíveis geradores de diferenciais aos seus produtos e serviços; se destacam dois indicadores do critério Clientes, dois do critério Informações e Conhecimento e um do critério Resultados. $\mathrm{O}$ 
quarto fator (explica 4,6\% da variância) identifica, gerencia e avalia a qualidade dos processos e produtos da empresa; os três indicadores com maior peso estão no critério Processos. O quinto fator (explica 4,2\% da variância) examina como a empresa avalia e analisa o desempenho dos processos de produção e econômico financeiros; os três indicadores de maior peso pertencem ao critério Resultados.

\section{Conclusões}

Os índices de liderança encontrados nas regiões cafeeiras avaliadas mostram capacidade empreendedora e comprometimento elevados dos empresários com a produção de café, que podem estar sendo em grande parte desperdiçados pela baixa aptidão ao planejamento. Isso ocorre tanto no estabelecimento de objetivos e cumprimento de metas, como da comparação e análise de problemas, fatores críticos e implementações de ações corretivas e resultados. A sistematização de informações e o uso de ferramentas administrativas e contábeis, mesmo que simples e de fácil aplicação, não estão presentes nas rotinas administrativas das propriedades. A falta de tempo, o baixo grau de instrução - a aplicação de formulários impressos identificou elevado índice de empresários com dificuldade em ler e escrever - e capacitação, somadas ao número reduzido de colaboradores inibem avanços efetivos nos aspectos de gestão que poderiam mudar esse quadro. Consequentemente, em geral as tomadas de decisão não são baseadas em protocolos ou números que conduzam à racionalização da produção.

O compartilhamento de opiniões e ideais (conceito de visão), somente na forma verbal, mesmo entre os membros de uma mesma família, não bastam para definir as ações futuras da atividade e da propriedade cafeeira, comprometendo sua sustentabilidade. Além da competitividade e sobrevivência da atividade, melhoria da qualidade do produto e agregação de valor, é preciso dotar o cafeicultor de uma visão estratégica de longo prazo inclusive, preparando a propriedade para a sucessão familiar e patrimonial. Apresentar aos empresários rurais ferramentas modernas de gestão, a começar do Plano de Negócio, é tarefa urgente dos agentes de extensão rural e técnicos da iniciativa privada que atuam no segmento cafeeiro. Se a grande maioria dos cafeicultores não identifica sua atividade como um negócio passível de organização, não sabe definir metas e aferir resultados, a busca da melhoria contínua de seus processos é prejudicada e, consequentemente, o desenvolvimento de regiões onde predominam a cafeicultura e pequenas empresas rurais é prejudicado.

O estímulo externo para que ocorra a estruturação do agronegócio café, na forma de preços diferenciados, auferidos pela comercialização dos chamados cafés especiais, é bom exemplo de que há caminhos possíveis. Mas melhores remunerações dependem de fatores como condições edafoclimáticas favoráveis, capacidade pessoal e acesso à informação. Quanto àquela essa remuneração, apesar dos esforços das cooperativas e associações de cafeicultores, estas não conseguem cumprir com o papel de formar e informar adequadamente seus afiliados, já que 80\% dos empresários se declararam associados ou cooperados, portanto há no mínimo, uma falha de comunicação. No Paraná há inclusive cooperativas criadas em função da cafeicultura e que atualmente se recusam a beneficiar o café de seus cooperados, priorizando outras atividades agrícolas.

No critério Pessoas cabe destacar o baixíssimo índice de amparo à saúde dos próprios empresários rurais e de seus colaboradores. No quesito de capacitação em operações de equipamentos e máquinas e no uso de EPIs os índices são relativamente satisfatórios, embora apresentem espaço para evoluir bastante.

Quanto aos aspectos sociais e ambientais, os cuidados relativos ao tema têm sido respeitados. A continuidade das ações educativas e de fiscalização deve garantir 
posição de destaque da cafeicultura paranaense nesse critério de preservação ambiental.

Apesar dos índices de busca por informações e conhecimentos externos à organização serem relativamente elevados, o acesso à internet ainda é baixo, bem como é muito baixo o índice de registro de informações internas à organização, dificultando o controle efetivo da atividade. Esses valores baixos evidenciam outra face do problema, não percebida pelos empresários rurais: a possibilidade de comparação de situações similares ao longo do tempo e a capacidade da organização em reproduzir processos e consequentemente resultados, a partir de sua própria experiência e memória.

A utilização de crédito agrícola é rotineira para grande parte das organizações e contrasta com os baixos valores de utilização do seguro rural, utilizados apenas devido à obrigatoriedade de contratação quando da aquisição de novos equipamentos e máquinas. Ou seja, a visão empresarial de gestão de crédito e a administração de riscos na cafeicultura paranaense ainda é muito limitada.

Quanto aos indicadores de resultados, aqueles mais voltados às questões de custos e de controle de produtividade obtiveram resultados medianos. Não há preocupação dos cafeicultores com a percepção e identificação de satisfação da qualidade junto aos seus clientes diretos e menos ainda com o consumidor final.

Conclui-se, portanto, que independentemente do tipo de café ou região avaliada do estado do Paraná, há um amplo potencial de crescimento das práticas de gestão em seus diferentes aspectos. Planejamento, sustentabilidade, ambiente, atendimento aos clientes, qualidade, agregação de valor e outros conceitos importantes para o desenvolvimento de um verdadeiro empresário rural ainda não foram incorporados plenamente à atividade cafeeira.

\section{REFERÊNCIAS}

BLISKA JÚNIOR, Antonio et al. Validação do método de identificação do grau de gestão na produção cafeeira utilizando grupo focal. Revista de Economia Agrícola, São Paulo: Instituto de Economia Agrícola, v. 62, n. 1, p. 41-54, 2015.

BOLFARINE, Heleno; BUSSAB, Wilton de Oliveira. Elementos de Amostragem. 1 ed. São Paulo: EditoraEdgard Blücher, 2005. 290 p.

BRONZERI, Márcia de Souza; BULGACOV, Sérgio. Estratégias na cadeia produtiva do café no Norte Pioneiro do Paraná: Competição, colaboração e conteúdo estratégico. Organizações Rurais \& Agroindustriais, Lavras, v.16, n.1, p.77-91, 2014

CARLI, Priscila Magalhães de; OLIVEIRA, Luciel Henrique de; DIAS, Eduardo Carvalho. Impacto da certificação Rainforest Alliance na gestão de uma propriedade de café no Sul de Minas Gerais. In: SIMPÓSIO DE PESQUISA DOS CAFÉS DO BRASIL,8., 2013, Salvador - BA. Anais...Salvador: Consórcio Pesquisa Café,2013.

CONAB. Companhia Nacional de Abastecimento. Acompanhamento da safra brasileira - V. 5 - SAFRA 2018 - N.4 - Quarto levantamento, Brasília: CONAB, Dezembro 2018, 84p.

DIEESE. Departamento Intersindical de Estatísticas e Estudos Socioeconômicos. Anuário da Saúde do Trabalhador 2015. São Paulo: DIEESE, 2016. 256 p.

HAIR JÚNIOR, Joseph et al. (Orgs.). Análise multivariada de dados. Tradução. Adonai Schlup Sant'Anna. 6 ed. Porto Alegre: Bookman, 2009. 688 p. 
IBGE. Instituto Brasileiro de Geografia e Estatística. Censo Agropecuário 2006. Disponível em: www.ibge.gov.br. Acesso em 21 de setembro de 2015.

IBGE. Instituto Brasileiro de Geografia e Estatística. Censo Agropecuário 2017. Disponível em: www.ibge.gov.br. Acesso em 31 de outubro de 2019a.

IBGE. Instituto Brasileiro de Geografia e Estatística. Divisão Regional do Brasil. Disponível: https://www.ibge.gov.br/geociencias/organizacao-do-territorio/divisaoregional/15778-divisoes-regionais-do-brasil.html?edicao $=16163 \& \mathrm{t}=$ sobre. Acesso em o7 de outubro de 2019b.

IBGE. Instituto Brasileiro de Geografia e Estatística. Produção Agrícola Municipal. Disponível: https://sidra.ibge.gov.br/tabela/1613. Acesso em 10 de outubro de 2019c.

INCRA. Instituto Nacional de Colonização e Reforma Agrária. Classificação dos Imóveis Rurais. Disponível em: http://www.incra.gov.br/tamanho-propriedadesrurais. Acesso em 16 de fevereiro de 2017.

KOHLHEPP, Gerd et al. Colonização agrária no Norte do Paraná: processos geoeconômicos e sociogeográficos de desenvolvimento de uma zona subtropical do Brasil sob a influência da plantação de café. Editora da Universidade Estadual de Maringá: EDUEM, 2014.

MF/DATAPREV. Ministério da Fazenda, Secretaria de Previdência, Empresa de Tecnologia e Informações da Previdência. AEPS-2015. Anuário Estatístico da Previdência Social 2015. Brasília: MF/DATAPREV, v. 24, 2015. 917 p.

PASTORE, J. O custo dos acidentes e doenças do trabalho no Brasil. Palestra proferida no Tribunal Superior do Trabalho em 20/10/2011. Disponível em: http://www.josepastore.com.br/artigos/rt/rt_320.htm. Acesso em 16 de fevereiro de 2017.

PIMENTEL GOMES, Frederico. Curso de estatística experimental. 15 ed. Piracicaba: FEALQ, 2009. 451p.

POZZOBON, Irineu. A epopéia do café no Paraná. Londrina: Grafmarke, 2006.

STECA, Lucinéia Cunha; FLORES, Mariléia Dias. História do Paraná: do século XVI à década de 1950. Londrina: Editora UEL, 2002. 205p.

VOLSI, Bruno et al. The dynamics of coffee production in Brazil. Plos One, [s.l.], v. 14, n. 7, p.1-15, 23 jul. 2019. Public Library of Science (PLoS).

http://dx.doi.org/10.1371/journal.pone.0219742. Disponível em: <https://journals.plos.org/plosone/article?id=10.1371/journal.pone.0219742>. Acesso em 15 de outubro de 2019.

VEGRO, Celso Luís Rodrigues; BLISKA, Flávia Maria de Mello. Evolução e participação da cadeia produtiva do café do Estado de São Paulo no agronegócio brasileiro. In: BLISKA, Flavia Maria de Mello; GUERREIRO FILHO, Oliveiro (Org.). Prospecção de demandas na cadeia produtiva do café no Estado de São Paulo. Campinas: Instituto Agronômico, 2007, p.15-19.

WACHOWICZ, Ruy Christovam. História do Paraná. $10^{\text {a }}$ ed. Curitiba: Imprensa Oficial do Paraná, 2002. 36op. 
Submetido em 10/01/2019 Aprovado em 04/3/202O

\section{Sobre o(s) Autor(es):}

\section{Antonio Bliska Júnior}

Engenheiro Agrônomo, Dr., Coordenadoria de Extensão. Email: bliskajr@feagri.unicamp.br

\section{Dimas Soares Júnior}

Engenheiro Agrônomo, Dr, Coordenador da Área Técnica de Socioeconomia e Coordenador Estadual das Redes de Referências para Agricultura Familiar. Email: dimasjr@iapar.br

\section{Patrícia Helena Nogueira Turco}

Graduada em Ciência da Administração Rural, Dra., Departamento de Gestão Estratégica da Apta. Email: patyturco@apta.sp.gov.br

\section{Flávia Maria de Mello Bliska}

Pesquisadora Científica Efetiva, nível VI, Centro de Café 'Alcides Carvalho'.

Email: bliska@iac.sp.gov.br 